ISSN 1112-9867

Available online at

http://www.jfas.info

\title{
SUSTAINABLE ARCHITECTURE APPROACH IN DESIGNING RESIDENTIAL- RECREATIONAL COMPLEX (QOTUR SUIE MESHKINSHAHR, ARDEBIL PROVINCE, IRAN)
}

\author{
S. Hamidzadeh ${ }^{1}$, S. Hamidzadeh Khiavi ${ }^{2}$ \\ ${ }^{1}$ Department of Art and Architectuer, Islamic Azad University, Jolfa Branch, Jolfa, Iran \\ ${ }^{2}$ Department of Art and Architectuer, Islamic Azad University, Shabestar Branch, Shabestar, Iran
}

Published online: 15 May 2016

\begin{abstract}
Sustainable architecture has been shaped with vernacular materials based on the vernacular architecture according to climatic conditions, saving energy and responding to needs and social and cultural conditions. In cold region architecture, the buildings are constructed as steps on the hills in the direction of sun and behind the west winds and with flat roof as function of environment. In this research, the effects of energy saving in architecture and vernacular architecture on sustainable architecture have been examined. This research was conducted based on identification, description and analysis and its aim was to reduce environmental damage and minimizing energy consumption and coordination with nature as the infrastructure of sustainable design philosophy. The results showed that designing a residential and recreational complex in the Qotur Suie touristic zone located in the touristic circle of Sarab, Meshkinshahr and Ardebil based on sustainable architecture for surviving vernacular design with artificial environment in a natural environment can protect the nature providing comfort for people and prevent its destruction.
\end{abstract}

Keywords: sustainable architecture, artificial environment, natural environment, new energy, Meshkinshahr province

Author Correspondence, e-mail: hamidzadeh.so@iaushab.ac.ir

doi: http://dx.doi.org/10.4314/jfas.v8i3s.14

\section{INTRODUCTION}

Sustainable architecture reduces energy consumption in the building and provides comfort for citizens.

This design emphasizes interaction between human and natural resources (1). The designing of a 
sustainable building that meets all sustainable requirements is often a challenge to the building professionals and building designers (2).

Energy is one of the strategic and important issues. It is obvious that by smart designing we can employ the environmental capabilities and remaining fewer damages (3). The goal of energy management is reduction of energy consumption with economic justification without negative consequences in comfort of the occupants (4). Optimal designing of a residential and recreational complex should provide opportunities for physical and mental revitalization and residential space reflects social, cultural and recreational policies (5). In recent years, low energy consumption buildings have been gained attention of the designers. Numerous studies have been done on building architecture characteristics and materials replacing for energy (6). The most important issue in relevance to these buildings according to density of the occupants in limited area is high energy consumptions whether during construction or occupation. Hence it is necessary to consider solutions for solving this problem and using renewable energies as the major goal of sustainable architecture (1). The other issue is locating these complexes in the touristic areas and this issue has let to destruction of nature that necessitates considering sustainable architecture principles in designing these complexes. The main issue of designing residential and recreational complex with sustainable architecture can be introduced as sustainable architecture with components of energy consumption reduction, using clean energies and principles of sustainable architecture design.

\section{PROBLEM STATEMENT}

Nowadays tourism industry has expanded in all over the world and most countries could improve their situations and solve economic problems so that tourism industry income constitutes 6 percent of the world export (7). The first account of a tourist from unknown area is shaped mainly by architecture and a specific design remains in minds easily and it has a positive role in decision making. A tourist pays attention to two elements, first a situation for recreation and calmness and second benefit from services optimally. In other words, a tourist is interested in having proper facilities and environment. Closeness of the residency place to recreational targets facilitates achieving these goals (8). Construction of recreational location considering various tourists and their needs causes to various beneficial jobs for native people and also it can be considered as a factor for introducing of economic capabilities which is one of the important economic considerations in developing countries. Consumption means responsibility of using resources, producing garbage and finally, production of carbon dioxide that needs buildings provide consumption and reduce environmental incompatibilities (9). 


\section{SUSTAINABLE ARCHITECTURE}

Sustainable architecture has become one of the most widespread areas of focus in the scholarly studies related to build environments. Accordingly, with view to the environmental assessment and energy performance of buildings, it is vital to develop an overview of current theoretical perspectives, trends, applications and constraints towards the development of environmentally sustainable buildings (10). Approximately all definitions emphasize protection of environment as a context for development fulfilled by interaction among economic, social, cultural and environment development (11).

Imbalance in these elements causes to instability. Sustainable architecture considers intricate issues of nature, human and artifacts. It should be bear in mind that architecture was compatible with nature until nineteen century and in other words, buildings did not imbalance nature or destruct it, nowadays the aim of sustainable architecture is balance among nature, creatures and artificial environment (12).

Application of the concepts of sustainability and sustainable development goals for reduction of energy consumption and environment pollution in architecture has led to sustainable architecture.

\section{3-1-Sustainable architecture principles}

Sustainable architecture has its own principles and includes three steps:

Saving resources: this principle provides the context for proper utilization of the nonrenewable energies including fossil fuels and natural resources as renewable sources.

Designing for return to life cycle: this is the second principle and it is based on this fact that a material is changed from usable form to other forms without damaging it and one of its duties in prevention of environment pollution.

Designing for human: this is the most important principle rooted in the needs for preserving ecosystem chain elements which assure human survival (13).

\section{3-2-Necessity of construction of stable buildings}

Industrial revolution moved human to cities. By progress of technology, life style was changed and humans used fossil fuels as heating resource. As a result most of the natural lands and forests were destructed and air and noise pollution increased and the natural resources were used unlimitedly. Now we encounter with ending natural resources. By this attitude and necessity of solving problems, construction of green and sustainable buildings seems necessary (14). According to the study by Joelsson[15], with view to the effectiveness of green buildings towards decreasing the use of energy and its negative impacts on the environment, there are fundamental strategies including 'reducing the energy demands', 
'enhanced energy efficiency' and 'application of passive design techniques'. Likewise, the utilization of appropriate building envelopes is influential in more than half of the embodied energy distribution in a building, particularly in residential buildings (16).

\section{POTENTIALS OF MESHKINSHAHR REGION FOR USING SUSTAINABLE ARCHITECTURE}

Meshkinshahr is located in the slope of Sabalan Mountain and it has various spas. Due to historical, cultural, natural and tourism attractions, it is one of the resorts of the tourists. The mentioned site is located near power plant between Meshkinshahr and Sabalan Mountain. This case study has been chosen due to followings:

Placing in the province tourism ring and closeness to Sabalan resort

Lack of proper touristic space in the mentioned region

Presence of maximum tourists relative to other spas of this city

Beauty of the mentioned zone in Qotur Suie

Presence of tourists in cold and hot season due to therapeutic nature(17)(Fig. 1, 2, 3)

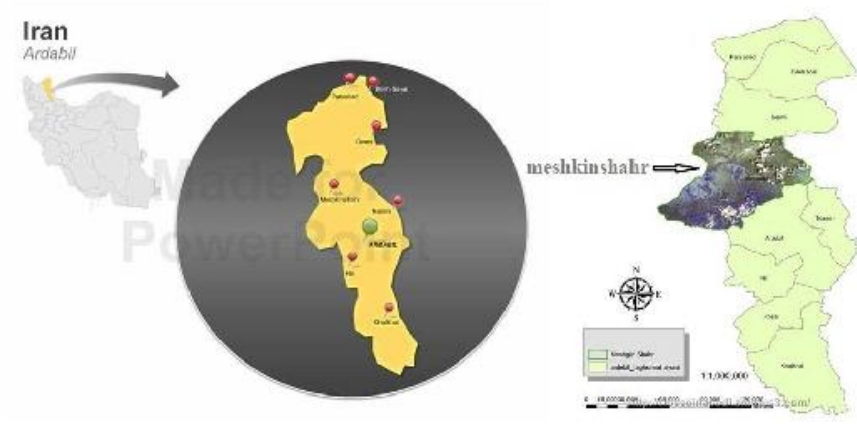

Fig.1. Iran-Ardebil province-Meshkinshahr

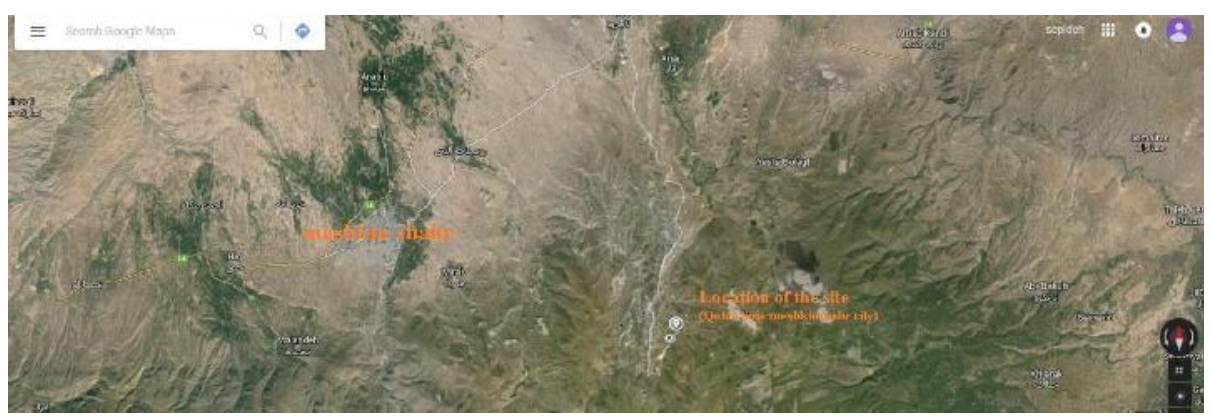

Fig.2. Mentioned site Satellite image in Meshkinshar 


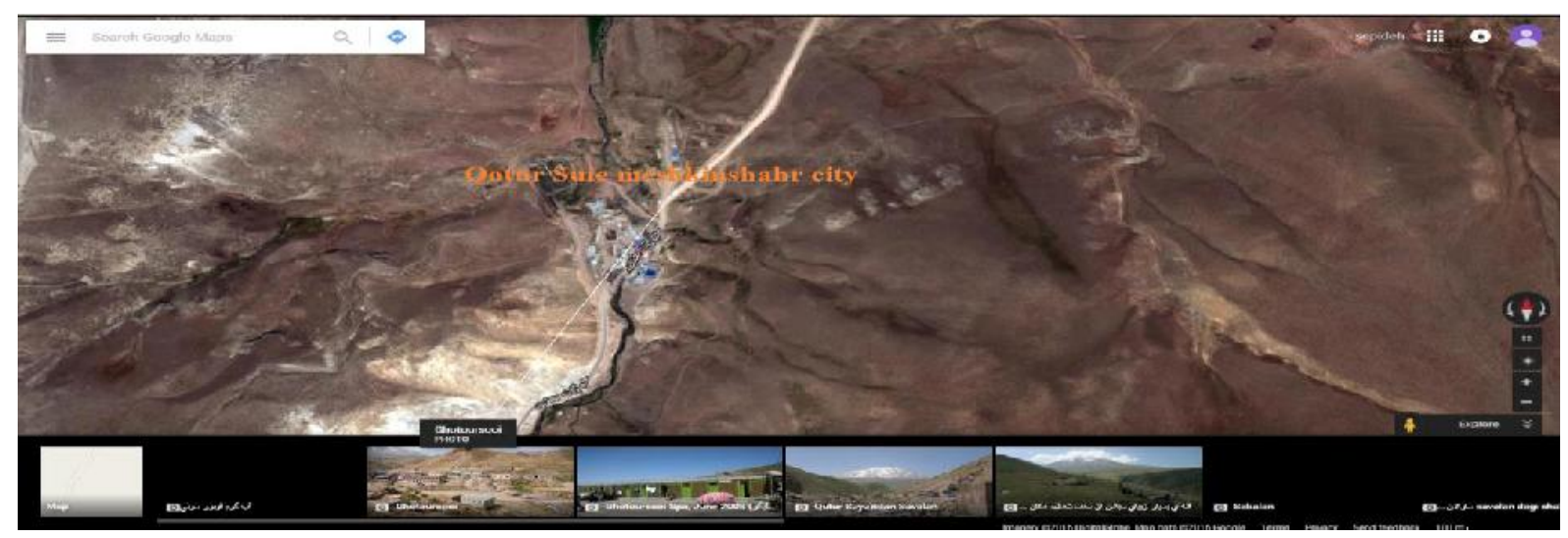

Fig.3. Meshkinshahr Qotur Suie aerial map (mentioned cite)

\section{4-1- Meshkinshahr climate}

Meshkinshahr is one of the Ardebil provinces with average height of 1416 meter from sea level located in latitude 380 23' 34" of north latitude and longitude 470 1' 7" east longitude of equator (18). The main tourism target is its various spas in the region and adjacent villages which are therapeutic due to physical and chemical properties (19). Hot and sulfuric water of Qotur Suie flow from Sabalan slopes in $24 \mathrm{~km}$ of Lahord town and $49 \mathrm{~km}$ of Meshkinshahr. Qotur Suie spa has free acid sulfuric and useful for treatment of the skin diseases. It is 42 centigrade and its flow is $13 \mathrm{l} / \mathrm{s}(20)$. The west of Ardebil has highest level of precipitation. The average annual precipitation varies 400 to $500 \mathrm{ml}(21)$.

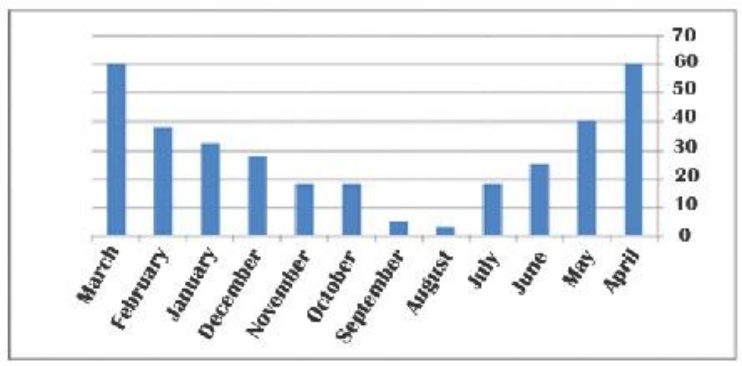

Graph 1. Annual precipitation Ardebil province (21) 
Table 1: Maximum precipitation in 24 hours of metrology synoptic station

\begin{tabular}{|c|c|c|c|c|}
\hline Station & Parsabad & Ardebil & Khalkhal & Meshkinshahr \\
\hline $\begin{array}{c}24 \text { hours } \\
\text { precipitation }\end{array}$ & $94 \mathrm{~mm}$ & $63 \mathrm{~mm}$ & $46 \mathrm{~mm}$ & $46 \mathrm{~mm}$ \\
\hline Date & $\begin{array}{c}26 \text { September } \\
1996\end{array}$ & $\begin{array}{c}5 \text { November } \\
1995\end{array}$ & $\begin{array}{c}9 \text { December } \\
1999\end{array}$ & 24 April 1995 \\
\hline
\end{tabular}

Resources (21)

\section{STRATEgIES FOR BUILDINGS HEATING, COOLING AND NATURAL VENTILATION IN THE MOUNTAINOUS CLIMATE}

\section{5-1- Typography sub-climates (cooling and heating)}

Prediction of sub-climate in a site:

1-Air flow resultant from concentration which the air is cold in bottom and hot at the top

2-Changing temperature by changing height

For each $100 \mathrm{~m}$ the height becomes cold $80 \mathrm{c}$ and temperature is low in heights.

3- Changing sunlight by changing the earth condition

It means combination of slope and orientation relative to sun

Surface vertical on sunshine(normal)

South slopes use more solar energy

Morning light in east direction

Evening light in west direction

4- Water big masses adjust daily and annual temperature

5-High Mountains have slopes against wind flow

\section{5-2-Cold regions climatic goals}

The goal is maximizing the solar heating in the winter and reduction of the winter winds effects in south slopes for increasing sunshine; it should be lower so that protect building against wind and upper to protect building against cold air basin in the floor(Fig.1). 


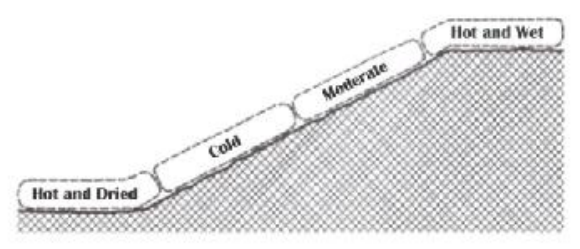

Fig.4. Slope situation based on climate

\section{5-3-Solar envelopment (natural heating and lighting)}

It means the highest volume that a defined site cannot shed on the adjacent site. The size and form of solar envelopment varies according to orientation and latitude and hours that sunlight s (Fig. 2).

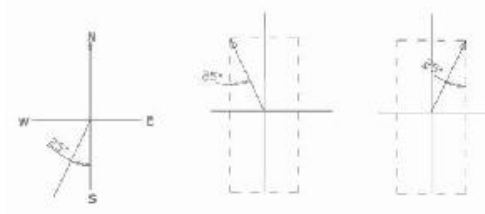

Fig.5. Size, orientation and latitude

\section{5-4- East and west buildings groups (heating)}

These buildings absorb highest solar energy and they have distance from north and south that angle of radiation is low even in the winter and the height of building does not prevent sunshine.

\section{5-5-Wind breakers (heating and cooling)}

Wind breakers can be used for creating borders that protect buildings and open spaces. For preventing winds blowing in one direction L shaped wind breakers can be used. Reduction of wind velocity in an area surrounded by trees depends on height, density, cross section shape, length and width (22).

\section{ECOSYSTEM DATA FEEDBACK EFFECT ON THE OCCUPANTS' BEHAVIOR}

In response to increase of costs and concerns about greenhouses gases, the researchers have proposed ecosystem data feedback systems and energy consumption information. The characteristics of these systems are quantitative data and manner of energy consumption. These data can have a significant effect on energy consumption behavior. If these systems are designed well with energy efficacy criteria can prove required change mechanism for sustainable energy consumption in the society (23). 


\section{EFFECTIVE FACTORS IN ENERGY CONSUMPTION AND COMFORT TEMPERATURE IN WTSW HOUSES}

The PSH houses collect sunlight $\mathrm{s}$ by building structure and productivity of the building materials. The various elements of the building coverage have different effect on the building energy consumption and interior optimal temperature. These houses can reduce $8.6 \%$ of energy consumption in a year and improve interior optimal temperature $12.9 \%$ (24).

\section{BUILDING ENERGY}

Building energy is divided into latent energy and apparent energy. The latent energy is consumed in process of production of materials or construction of buildings and human energy and fossil energy in machineries related to construction of building are examples of this type of energy. The apparent energy issued after construction of building and these energies are divided according to type of consumption (25).

\section{RENEWABLE ENERGIES}

Fossil fuel is the main energy source nowadays, but there are two challenges when using fossil fuels. One is the limit of its storage, which will increase the energy price and give rise to the concern of energy security; the other is its damage to the environment, especially the emission of greenhouse gas. Energy policies therefore focus on retraining consumption of fossil fuels at the demand side, and developing alternative energy sources at the supply side. In 2012, fossil fuels, like oil, natural gas and coal, share over 50\% of the energy sources in most countries (26) and to decrease the dependence on the fossil fuels.

In light of the economic and societal growing concerns over global warming caused by fossil fuel, high volatility of energy prices, and high growth of energy needs, clean energy (e.g., hydroelectric, new renewable, and nuclear) has become an important alternative energy source for fossil fuel(27). These powers can be obtained directly from nature, and generate less pollution during the transformation and consumption process (26).

The cases used for clean and renewable energies can be mentioned as follows as energy consumption factors in order to create sustainable architecture in Meshkinshahr:

\footnotetext{
$\checkmark$ Solar energy

$\checkmark$ Wind energy

$\checkmark$ Geothermic energy
} 


\section{CONCLUSION}

Reducing energy consumption and sustainable designing is necessary even in the areas that are called protected and the nature decline can be controlled by these designs. The study discussed about the essence of sustainability for enhancement of building energy efficiency. The findings clearly represent versatile parameters for improving the energy performances of green and sustainable buildings. These parameters are derived from interdisciplinary studies with view to the design, construction, maintenance and user studies. It is believed that the proposed solutions for enhancement of sustainable energy performances of buildings could be widely used for the sake of creating environmentally responsive cities (27).

It is said that the northwest cities and villages in Iran encounter with specific problems. The old texture of the cities is destructed and more energy is consumed due to cold climate. In this regard, energy is the most important element and due to this fact that renewable energies are used less in these areas, using new energies such as wind turbines, photovoltaic glasses and solar heaters and geothermic energy in Meshkinshahr region and also architectural arrangements have been investigated.

\section{0-1-Propositions in designing residential and recreational complex with sustainable architecture approach}

The followings can be proposed:

Offering information in the feedback systems can have significant effect on energy consumption

Using PSH traditional walls equipped with WTSW can reduce energy consumption and improve interior optimal temperature till $12.9 \%$.

Using doubled walls and classes in the south direction for optimal usage of solar energy and using thermal insulators and openings and sealing the seams.

Using doubled facades for energy saving

Using solar heater for heating water and energy saving

Using photovoltaic cells for meeting energy in external facades

Using grasses for reflection of sun ray and heating the complex

Providing vegetation around building facades for converting dioxide carbon to oxygen

Using trees in the wind direction for reducing wind velocity in the site

Making dense the complexes

Construction of ramps on the typography levels for minimum evacuation

Using geothermic energy of Meshkinshahr for supplying the complex fuel

Using flat roof due to cold weather and insulating and reducing noise transfer 
Using wind turbines installations in the site

Using solar panels for saving energy and use surplus energy

Ten percent natural ventilation of the complex

Using radiation heating system in the winter

Using recyclable materials and replaceable energy designs and employing technology and new materials

Using aggregates due to the following reasons:

Saving energy in transportation of materials

Aggregates in relevance to climate that in case of destruction do not damage the nature

Less interference with nature in terms of beauty

Proportional with climate that due to black color absorb thermal energy in day and having maximum thermal mass (29).

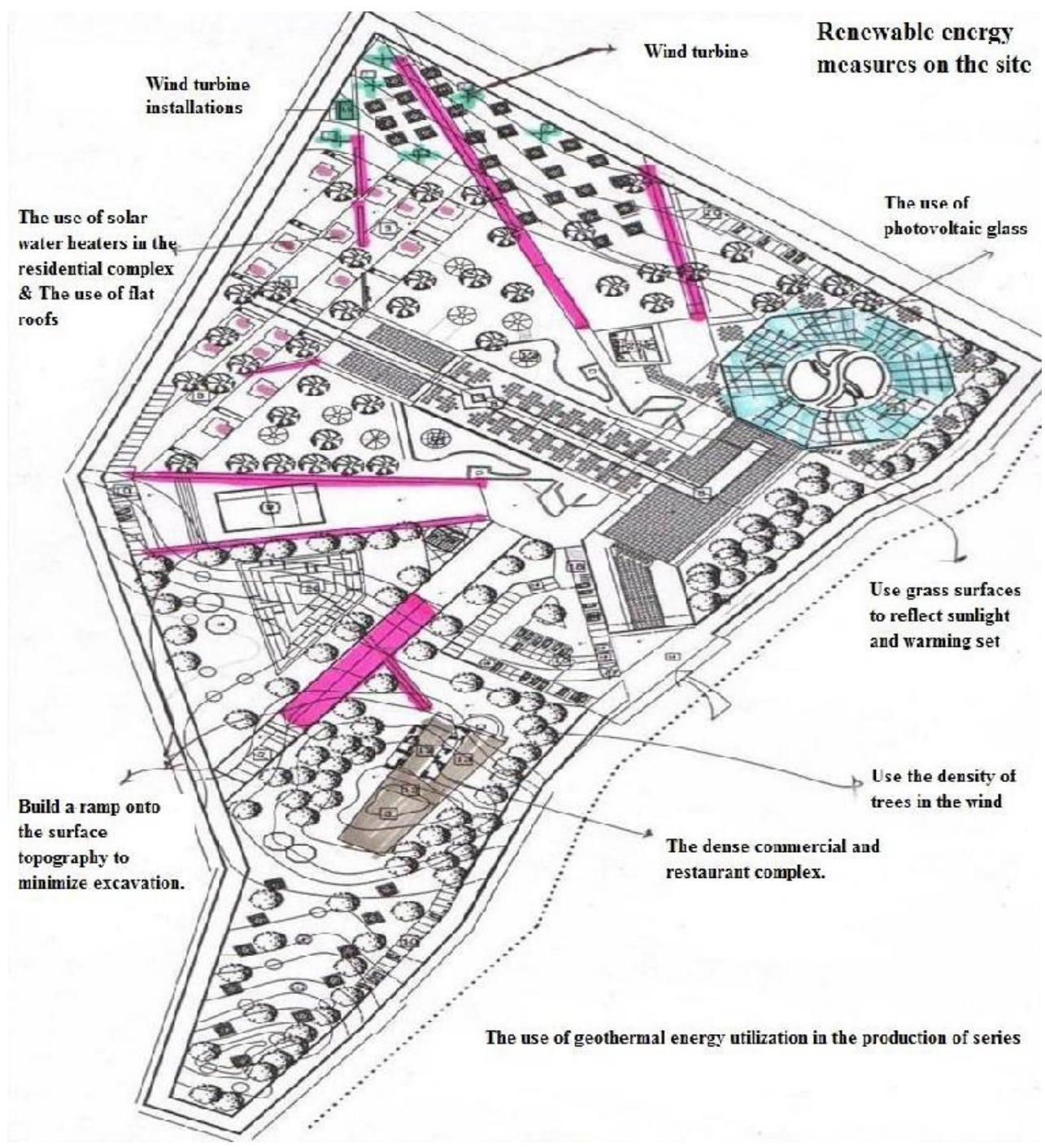

Fig.6. Proposition for the site 


\section{REFERENCES}

Mirzaei TazehKandi, M. "Designing sky scrapers with sustainable architecture approach", International conference on Architecture engineering and urban sustainable development, Tabriz, 18, 19 December, 2013

Taheri, Bahreh. “Amol residential and recreational complex with sustainable architecture approach, M.A thesis, Dr. Egbali, International University of Imam Khomeini, 2006

Sharifyan, A., Vaziri, B.; Sattari Sarbangoli, H. Proposing architectural solutions in designing residential and recreational complex in relation to empowerment of tourism industry, the 1st national tourism management and geography, Hamadan Shahid Mofateh University, 2013

Sabgh Kermani, A.. Investigating the tourism industry state and estimation of tourism demand and supply, Fundamental Research Center, Ministry of Culture and Islamic Guidance, Tehran, 1996

Sohrabi, B.; Tahmasbipour, K.; Raesi, I.; fazli, S. Identification of the measures and explaining fuzzy sets for selection of hotel from the Tehran tourists, Human geography research, no. 79, pp, 55-74, 2012

Afshar Naderi, K. Architecture and environment, Journal of Architect, no. 48, 2008

Jodat, M. Architecture and sustainable architecture, Iran Architecture Quarterly, no. 23, 2004

Dariush, B. Human, nature and architecture, Iran Architecture Journal, 2010

Field studies(2014)

Saedi, Golam Hussein, Khyav( Meshkinshahr), Amir Kabir puplication, 2nd edition, Tehran, 1975

Articles of Architectural regional and building in Azerbaijan conference and its effect on sustainable development, March 2009, Meshkinshahr, 1st edition, 2011

ISNA report in Ardebil, Iran Students Press, 2013

Ardebil province metrology office database, 2008

Kasmaei, M. Climate and architecture, Khak publication, 5th edition, Tehran, 2003

Azimi Bloriyan, A. Energy in the building, Journal of Architect, no. 48, March and April 2008, Author data processing(2015)

\section{How to cite this article:}

Hamidzadeh S, Hamidzadeh Khiavi S. Sustainable architecture approach in designing residential-recreational complex (qotur suie meshkinshahr, ardebil province, iran). J. Fundam. Appl. Sci., 2016, 8(3S), 1037-1047. 